\title{
Na confluência das tradições: entrevista a Nuno Júdice
}

artindo de uma ideia de Silvana Pessoa de Oliveira, esforçámo-nos para juntar a este dossier temático uma entrevista de Nuno Júdice. Agradecemos muito ao poeta por nos ter recebido na sua casa ao Campo Pequeno e nos ter facilitado acesso à sua "arca". O resultado, como o leitor verá, ficou porventura bem equilibrado entre um pensamento sobre a própria poesia e a forma como esta se relaciona com a história da poesia portuguesa dos séculos XIXe XX, e daí o título da entrevista.

DDB - Começaria por remeter para o seu último livro de poemas, ["Fórmulas de uma luz inexplicável", D. Quixote, 2012]. Pareceu-me que a questão da memória pessoal tem um papel forte neste livro, mas por outro lado também não é uma questão nova, é uma questão que já tem aparecido...

NJ - A poesia é sempre feita de memórias, quer memórias reais, quer imaginárias, por isso muitos dos meus poemas põem em cena situações em que há um eu que se relaciona com o real de uma forma que nem sempre corresponde a algo que tenha acontecido. Portanto, é uma ficção da memória, no fundo; é um processo de construção que procede por analogia com essa poesia mais pessoal, mais individual que de certo modo foi "inventada" pelos românticos. E é uma forma também de reconstrução do processo de utilizar a memória como um instrumento de trabalho, de criação poética. 
DDB - Mas em que medida essa questão o preocupa mais hoje do que antes?

NJ - [risos] ... Possivelmente porque estou a perder a memória, portanto é uma maneira de ir guardando coisas que, digamos, estão em risco, mas ao mesmo tempo isso também tem a ver com o facto de ser a distância a que estou de determinadas coisas que me permite ter um outro olhar e uma outra possibilidade de as transformar que, quando se está muito perto dos acontecimentos, não é possível ter.

DDB - E a questão religiosa, metafísica, também passa por ela um pouco...

NJ - Tive essa educação, portanto isso sempre aconteceu, sempre existiu: nos primeiros livros através de um certo regresso ao Paganismo onde quem está presente não é Deus mas os deuses, numa visão um pouco panteísta do Universo. Recentemente, nos últimos livros, Deus ganhou uma certa individualidade como sujeito também deste mundo poético. E é a maneira, no fundo, de centrar numa ideia aquilo que com a visão pagã do sagrado se multiplicava por imagens diversas. Há talvez uma forma de ir ao centro do problema em vez de passar por essas derivações que são as vénus, os apolos, enfim, todos esses deuses antigos.

DDB - E também me pareceu aparecer aqui aquela província portuguesa pobre, mas de antigamente...

NJ - Desde "A noção de poema" [1972] sempre esteve presente - é a memória da infância, da adolescência. Esse contraste entre o mundo dos pobres e os ricos - aqueles que tinham de facto o poder, que não só era o poder do dinheiro mas também o poder político - é uma coisa que é recorrente no que eu escrevo. Talvez surja de uma maneira mais explícita na ficção, mas tem passado recentemente também para a poesia. 
DDB - Numa afirmação sua retirada de uma entrevista que deu à revista "LER" [n¹14, 2012] diz algo que me pareceu central dentro do que afirmou, e que ficou talvez um pouco por explicitar. Aí diz que na sua poesia "há uma confluência de várias tradições da poesia portuguesa". Parece-me que isto seria uma frase que daria, só por si, para um bom comentário... [risos]

$\mathrm{RM}$ - Ou uma tese... [risos]

NJ - [risos] Sim, evidentemente aquela queé mais forte é a que vem do Modernismo de Pessoa porque foi aquela que, de certo modo, marcou a escrita na minha adolescência, sobretudo Álvaro de Campos e o Mário de Sá-Carneiro. Mas para lá disso há uma marca que nunca perdi da poesia do século XIX, não tanto Cesário Verde, que é por todos considerado o grande inovador, mas uma poesia mais ligada, por um lado, à filosofia, caso do Antero deQuental, por outro lado a essa memória de infância, e a essa relação com a província, que é a do António Nobre. Para mim são talvez os dois poetas que me tenham marcado mais nesse período. Depois, evidentemente, há muitas outras tradições, desde o Camões, mas também no século XX: Florbela Espanca, o Gaspar Sim...

DDB - [risos $]$

$\mathrm{RM}-[$ risos]

NJ - [risos] ... o Jorge de Sena. Pensava no Gaspar Simões porque me lembrei de uma ideia que deu título a um dos livros dele que é "O Mistério da Poesia" e no fundo é essa a questão: que cada poeta tem em si esse mistério que só ele pode decifrar. No fim, são os poetas que dão forma a esse mistério que me interessa. Aqueles onde há o enigma, qualquer coisa que atravessa e percorre essa poesia, e portanto não são os poetas mais evidentes (mesmo que sejam muito interessantes) que eu procuro e que são produtivos para a minha escrita. 
DDB - Então pode-se dizer que no fundo também através da sua poesia revisita, reconstrói o próprio cânone poético...

NJ - Bem, o objectivo não é esse; isso acontece com todos os poetas que leio e que me tocam. Portanto é, por um lado, um diálogo com eles - retomar as suas preocupações e os seus temas e ver em que medida a minha relação com essas ideias, imagens, joga com as deles. O ponto de partida é esse diálogo e é depois para ir mais além e encontrar uma nova formulação dessa questão essencial da poesia - o que é o mundo, o que é o homem, enfim, o que é a vida. São essas as três questões.

DDB - Precisamente pegando nessa relação entre poesia e mundo pareceu-me que havia um poema muito esclarecedor sobre essa questão, ou também muito enigmático, em que descreve uma visita a Perugia ["O equívoco das ruas"], aí dáse por si procurando a diferença entre o que seria poético ou não, e de repente o mundo devolve essa resposta...

$\mathrm{NJ}$ - Isso tem a ver com a minha relação com as cidades - e com a cidade. Isto porque, como viajo bastante, e mesmo quando não viajo, o que me interessa no espaço não é tanto a paisagem, o cenário, mas a forma como essa paisagem e cenário interferem no nosso mundo interior. Eolhar para as coisas é captar uma substância que pode ser às vezes o clima, determinados pormenores da arquitectura, uma árvore, uma colina, o mar, um aspecto específico do mar. É, digamos, uma segmentação dessa totalidade queé dada por esse cenário, e encontrar a minha relação com ela através da parte. É o que na retórica chamamos uma sinédoque. E a poesia em que eu trato dessas coisas vai à procura do pormenor -é um pouco como esquecer a totalidade para me centrar nesse pormenor. Pode ser uma montra iluminada com qualquer coisa que está lá dentro, uma pessoa, uma cena de rua. É, no fundo, nessa segmentação que se concentra a totalidade do poema. 
RM - Isso lembra-me também uma pergunta que gostaria de lhe fazer e que se prende com o conceito de Realidade. Ontem discutia-se num colóquio na Universidade Nova de Lisboa se a Realidade e a Poesia não são a mesma coisa, nem sequer duas faces da mesma moeda. O que pensa sobre isso?

NJ - Eu acho que não [risos]. A Realidade é uma coisa e a Poesia é algo que está para lá dela. Estar para lá da Realidade significa por um lado que ela não está condicionada por essa realidade, não nasce dela, embora às vezes possa ser desencadeada por qualquer coisa que surgiu da relação com o real, mas ao mesmo tempo vai no sentido da procura de uma outra realidade que depois é sempre algo que vive por si, independentemente do ponto de onde o poema poderá ter nascido.

RM - Em vários poemas, há um recurso metapoético que é empregue para encerrar o poema. Se toda a literatura está condenada a ser auto-referencial, o que ganha o poema em explicitar essa dimensão?

$\mathrm{NJ}$ - O que acontece na minha escrita, e penso que é algo que dá forma ao processo de criação poética desde sempre, é que não posso esquecer quem escreveu antes de mim. Quem tenta fazer isso está condenado ou à repetição, ou à banalidade - de certeza que alguém já escreveu alguma coisa sobre isso e se não se conhece esse passado é muito difícil a um poeta, ou candidato a isso, adquirir a sua linguagem própria. Mas o conhecimento da poesia implica sempre uma reflexão sobre a poesia e sobre o que é esse conhecimento...

RM - De certa forma, cada poema é uma reflexão indirecta sobre o que é a poesia.

NJ - No meu caso, sim. 
RM - Pensando numa afirmação sua sobre não haver uma linguagem ruptural na poesia portuguesa de hoje, o que seria determinantemente ruptural na poesia portuguesa de hoje? Ou melhor, sem particularizar, com o que é que o poeta português do século XXI deveria romper?

NJ - [risos] É uma pergunta um pouco complicada porque neste momento a poesia portuguesa tem uma grande diversidade de vozes e de linguagens, e é ainda difícil encontrar aquilo a que se poderia chamar uma "organização" para essa diversidade. Por um lado porque são poetas muito novos e que começaram agora a publicar, e por outro lado porque há uma confluência de tradições diversas que vêm do século XX. De um século XX não exclusivamente português. Talvez o que seja interessante nesta nova poesia é ver que ela muitas vezes se afasta da nossa tradição, mas para falar em ruptura julgo que talvez onde se verifique uma procura de ruptura é num tipo de poesia que vem da desconstrução sintáctica à maneira da [Maria Gabriela] Llansol. É uma poesia que tenta romper com tudo aquilo que praticamente durante todo o século $X X$ foi uma constante e que é uma expressão comunicante dentro da poesia. $\mathrm{O}$ mundo poético pode ser muito complexo, muito hermético, mas a maneira de o transmitir, mesmo no Herberto Helder, por exemplo, é...

\section{DDB - ...regular?}

NJ - Sim, regular no plano frásico, gramatical.

RM - Tem uma poética própria.

NJ - Enquanto que a Llansol de facto trouxe uma desarticulação à escrita e é nesse aspecto que há alguns poetas novos que seguem isso. Por exemplo, uma Joana Serrado, entre outros. 
DDB - Cronologicamente a sua geração seria a mesma de um António Osório, mas também de um Joaquim Manuel Magalhães [JMM] ou João Miguel Fernandes Jorge [JMFJ], etc. ... NJ - Vasco Graça Moura...

DDB - ... olhando agora à distância acha que continua a fazer sentido falar dessa geração, incluindo a sua própria poesia nela, ou se pelo contrário, acha que se pode deslocar a sua inscrição nessa geração?

NJ - Não sei se dá para falar em geração. É digamos um grupo de poetas - alguns não tendo sequer relações pessoais na altura - não conhecia o Vasco Graça Moura, não conhecia o António Osório pessoalmente, e o que se poderia chamar esse grupo com que tinha uma relação pessoal era o João Miguel, o Magalhães, o Rui Diniz, o...

DDB - ...o António Franco Alexandre?

NJ - O Franco Alexandre pouco, mas o Manuel Gusmão sim, que só viria a publicar muito depois. Aí sim havia na altura um meio onde nós estávamos que era o da Faculdade de Letras [da Universidade de Lisboa], com tudo aquilo que se passava na altura na transformação intelectual e política, nas preocupações no que toca ao pensamento sobre o literário, quanto ao gosto...

DDB - Tinham todos idades muito próximas também, e estavam nos mesmos cursos...

NJ - Havia a diferença de alguns anos, em certos casos, mas havia um plano estético comum que era pertencermos a esse universo de conhecimento, por um lado sobre o que é a literatura e por outro lado de descoberta do que vinha de fora na altura. Eram todos aqueles movimentos novos, quer em França, mas também 
em Inglaterra, com a descoberta de poetas como Pound, Eliot, depois o Cavafy que começa nessa altura também a ser muito divulgado, bem como a revalorização de poetas portugueses como é o caso de Jorge de Sena, da Sophia, do Cinatti, e de outros que na altura não eram propriamente os canónicos...

DDB - Conheceu o Cinatti?

NJ - Falámos algumas vezes, mas muito esporadicamente. Mas foi sobretudo essa comunhão de gostos - estético, em relação quer à Literatura, quer ao Cinema, que forma uma linguagem que tem na sua base as mesmas interrogações, as mesmas preocupações, e muitas vezes os mesmos temas.... E sobretudo a procura de encontrar uma alternativa ao NeoRealismo, à poesia de intervenção, e portanto àquilo que era dominante naquele período. Igualmente importante na altura foi o aparecimento de uma crítica nova com o Eduardo Prado Coelho, o António Ramos Rosa, este com outro fundo, outra tradição, mas era gente que pensava a literatura (o David Mourão-Ferreira, também) de uma maneira mais ampla e mais inovadora, com essa relação directa sobre o que é o poético e o que é o literário, que era o que nos interessava.

DDB - Então só nesse enquadramento geral é que se pode falar numa geração?

NJ - Penso que sim.

DDB - Até porque a sua poesia também se afasta...

NJ - Como todas as outras, segue caminhos diferentes.

DDB-Um crítico como António Carlos Cortez (entre outros) opõe muito a Poesia 61 a esta poesia outra de 70, exemplificando 
sobretudo com o JMM e JMFJ, mas sustenta também que hoje em dia se reproduziriam também duas linhagens - uma mais ligada ao primeiro momento e outra mais ligada ao que vem dos anos 70. O que acha desta afirmação?

$\mathrm{NJ}$ - O que se costuma dizer quando se contrapõe a Poesia 61 a essa geração dos anos 70, é que há uma linguagem mais narrativa, mais descritiva na poesia de 70 que será uma resposta ao lado mais formal, ao chamado "trabalho sobre o significante", da Poesia de 61. Eu julgo que isso poderá ter acontecido em relação aos livros que marcam essa ruptura da Poesia 61 com a poesia anterior, mas é preciso ver que há poetas de 61 que depois vão evoluir no sentido de se aproximar muito dessa tal narratividade dos anos 70. É o caso da Fiama Hasse Pais Brandão. Portanto, essa oposição entre o que se poderia nomear o formal e o "conteúdo" era aquilo que, por comodidade, surgiu de apoio para estabelecer essa diferença entre os dois movimentos ou grupos dessa época. Hoje, com a distância, isso de facto esbateuse um bocado. Esse lado mais formalista da Poesia 61 foi superado pelos próprios poetas na evolução deles.

DDB - Então esta oposição seria, dum certo ponto de vista, um pouco uma construção...

NJ - Ela verifica-se, de facto, naquele momento. Quando nós surgimos, e os primeiros livros aparecem em inícios da década de 70 - lendo esses livros, eles efectivamente apontavam um caminho totalmente diverso da Poesia 61 e eram escritos com uma linguagem poética que, se fôssemos buscar um antecedente, seria esse verso longo do Nemésio, do Sena ...

DDB - Está a pensar igualmente no seu primeiro livro, "A Noção de Poema" [1972], porque ele recupera esse verso longo. 
NJ - Sim. E também no Herberto Helder, que foi no fundo a figura marcante para a minha geração, e um livro, que era "Passos em volta" [1961], um livro entre prosa e poesia.... enfim, todo em prosa, são contos, mas com um imaginário bastante poético.

DDB - Voltando um pouco atrás, à recente poesia portuguesa, que nomes então mais lê actualmente?

NJ - Tenho seguido a revista "Criatura" e os poetas que vão por lá publicando. Mas agora dos poetas mais recentes, surgiu uma antologia que se intitula "Meditações sobre o Fim" [Lisboa, Hariemuj, 2012] também com propostas interessantes, e algumas muito diferentes, que podem transportar atrás delas uma nova poética. Tenho seguido também o trabalho de poetas que vivem no estrangeiro, caso da Joana Serrado que corresponde a um tipo de escrita que se pode incluir na linha do "estrangeirado", poetas que recebem uma formação de espaços que não são cultural e linguisticamente os nossos...

DDB - No caso dela bem distantes, até, Países Baixos, Noruega,...

NJ - Bem distantes, sim. E por vezes esquecemo-nos, mas a Llansol também esteve na Bélgica. Portanto é uma tradição, esta de receber também os contributos culturais e linguísticos de fora, que estamos a ver nalguns poetas novos.

DDB - Mas pensa que mesmo na nossa geração esta questão do estrangeirado vs...

$\mathrm{NJ}-$...o castiço? [risos]

$\mathrm{RM}-[$ risos $]$ 
DDB - ...se poderia ainda manter?

NJ - Penso que sim. Infelizmente há ainda algumas poéticas que são muito "bairristas", isto é, algumas poéticas que pensam que ir buscar forma e inspiração lá fora é um provincianismo e vivem muito em função de coisas nacionais, e isso é bastante fechado e estéril.

DDB - Já que esta é uma entrevista a ser publicada no Brasil, o que tem acompanhado dos poetas brasileiros?

$\mathrm{NJ}$ - O meu diálogo com a poesia brasileira nasceu, de certo modo, numa fase já tardia do meu percurso poético, com a descoberta da importância de poetas como Carlos Drummond de Andrade e Vinicius de Morais, depois de João Cabral de Melo Neto, e também de Adélia Prado, de Manuel de Barros, de Ana Cristina César, e outros mais recentes. Mas quando comecei a ler a poesia brasileira também com este lado criativo, de encontrar formas de trabalho para a minha escrita, foi a partir dos anos 80 . Isto também se explica em parte porque foi nesse período (e nos anos 90 ) que a poesia portuguesa deixou de ser tão produtiva para mim.

\section{DDB - No sentido do diálogo?}

NJ - Sim. Para mim, os últimos poetas, para além dos anteriores, destas gerações mais recentes, que me interessaram e que continuo a acompanhar foi o Al Berto, bastante importante até na relação pessoal com ele de amizade. Mas depois a Ana Luísa Amaral, por exemplo. Verificou-se um esgotamento criativo no nosso final do século XX e só agora o século XXI parece estar a recomeçar a dar sinais de revitalização. O fim do século é sempre um período difícil, e este para a literatura portuguesa não sei se foi muito fácil. 
RM - Para terminar, uma provocação. Escolha entre uma ou outra. O "poeta é um fingidor" [Pessoa] ou "um mundo encerrado num homem" [Victor Hugo]?

NJ- Quando oiço esse tipo de perguntas, tenho logo a vontade de dizer "nem uma coisa nem outra"... [risos]

$\mathrm{RM}-[$ risos $]$

DDB - [risos]

$\mathrm{NJ}$-O que quero dizer com isso é que cada poeta é uma pessoa com um mundo pessoal e com a capacidade de dar uma figuração escrita a essa individualidade, e é por isso que para mim não existe a pessoa sem o homem - são duas coisas que estão estritamente ligadas.

Lisboa, 10 de novembro de 2012 Conduzida por Duarte Drumond Braga e Ricardo Marques 